\title{
Nocturnal hypertension—solving the puzzle of preeclampsia risk
}

\author{
Satoshi Hoshide ${ }^{1}$
}

Received: 2 September 2021 / Revised: 6 September 2021 / Accepted: 7 September 2021 / Published online: 25 October 2021

(c) The Japanese Society of Hypertension 2021

Preeclampsia is a complex syndrome complicated by various progressive disorders, such as hypertension, proteinuria, and end-organ dysfunction. Eclampsia is the development of seizures with severe preeclampsia. Preeclampsia/eclampsia (PE) is associated with an increased risk for serious morbidity and mortality in both mothers and neonates. In addition, several studies have reported that patients with PE have an increased risk of cardiovascular disease even over the long term [1].

There are several known risk factors for the development of PE. A previous meta-analysis of 92 cohort studies found that the most significant risk factor was prior preeclampsia and that the second most significant was chronic hypertension [2]. Chronic hypertension is conventionally defined as an office blood pressure (BP) of $\geq 140 / 90 \mathrm{mmHg}$ [3]. However, a BP guideline recently published in the US lowered the threshold for the definition of hypertension to $\geq 130 / 80 \mathrm{mmHg}$ in office BP for nonpregnant patients [4]. Several studies suggest that this new definition may also be acceptable for pregnant patients. For example, Wu et al. reported that those with stage 1a (130-134 mmHg in systolic BP and/or $80-84 \mathrm{mmHg}$ in diastolic BP) or stage $1 \mathrm{~b}$ hypertension $(135-139 \mathrm{mmHg}$ in systolic BP and/or 85-89 mmHg in diastolic BP) diagnosed in early gestation had significantly increased incidences of hypertensive disorders in pregnancy, including $\mathrm{PE}$, compared to normotensive women (adjusted odds ratio, 2.34 [95\% confidence interval, 2.16-2.53]; 3.05 [2.78-3.34], respectively) [5].

Several international BP guidelines recommend the assessment of out-of-office BP for the management of hypertension in nonpregnant patients, but the association between out-ofoffice BP and the risk of PE has not been widely studied [4]. Salazar et al. [6] investigated the association between out-ofoffice BP assessed by ambulatory BP monitoring (ABPM) and the risk of the development of late- or early-onset $\mathrm{PE}$ in a group

Satoshi Hoshide

hoshide@jichi.ac.jp

1 Division of Cardiovascular Medicine, Jichi Medical University School of Medicine, Shimotsuke, Japan of 477 high-risk pregnant women, which included women with prevalent hypertension, diabetes, collagen diseases or antiphospholipid syndrome and chronic renal diseases. Among these 477 individuals, 69 and 44 patients developed late- and earlyonset PE, respectively. The patients with nocturnal hypertension $(\geq 120 / 70 \mathrm{mmHg})$ had a risk of early-onset $\mathrm{PE}$ after adjustment for covariates including daytime BP (adjusted odds ratio, 5.26 [95\% confidence interval, 1.67-16.60]) but not a risk of late-onset $\mathrm{PE}$, while these associations were not observed in patients with daytime hypertension. Although the prevalence of early-onset PE is lower than that of late-onset PE, early-onset PE results in more adverse birth outcomes (such as very low birthweight and perinatal death) than late-onset PE. Therefore, the results of the study published by Salazar et al. provide an important strategy for the prevention of early-onset PE. However, in that study, it was not clear why nocturnal hypertension showed a greater association with PE risk than daytime hypertension. It has been proposed that soluble fmslike tyrosine kinase-1 (sFlt-1) secreted from a pathological placenta is strongly linked with the development of PE. sFlt-1 binds vascular endothelial growth factor and placental growth factor, and both of these binding events are known to lead to vascular inflammation, endothelial dysfunction and vascular injury. On the other hand, sFlt-1 is known to be associated with the presence of coronary artery disease and its severity in the nonpregnant population [7]. A previous study reported that the sFlt-1 level was also associated with brain natriuretic peptide (BNP) in ambulatory patients [8]. BNP is produced by cardiac tissue in response to volume overload. Although the mechanism underlying the association between sFlt-1 and BNP is not clear, it has been proposed to involve a direct effect of sFlt-1 on myocardial structure and function.

Increased nighttime BP is associated with a risk of cardiovascular events in both the general and hypertensive populations. In the Japan Morning Surge-Home Blood Pressure (JHOP) study, which is a prospective observational study exploring the association between home $\mathrm{BP}$ and cardiovascular events, both N-terminal-proBNP (NT-proBNP) and nighttime $\mathrm{BP}$ assessed by home BP monitoring were associated with cardiovascular events, and nighttime home BP mediated the 
Fig. 1 Association of nighttime blood pressure with preeclampsia/eclampsia
Soluble fms-like tyrosine kinase-1 (sFlt-1)

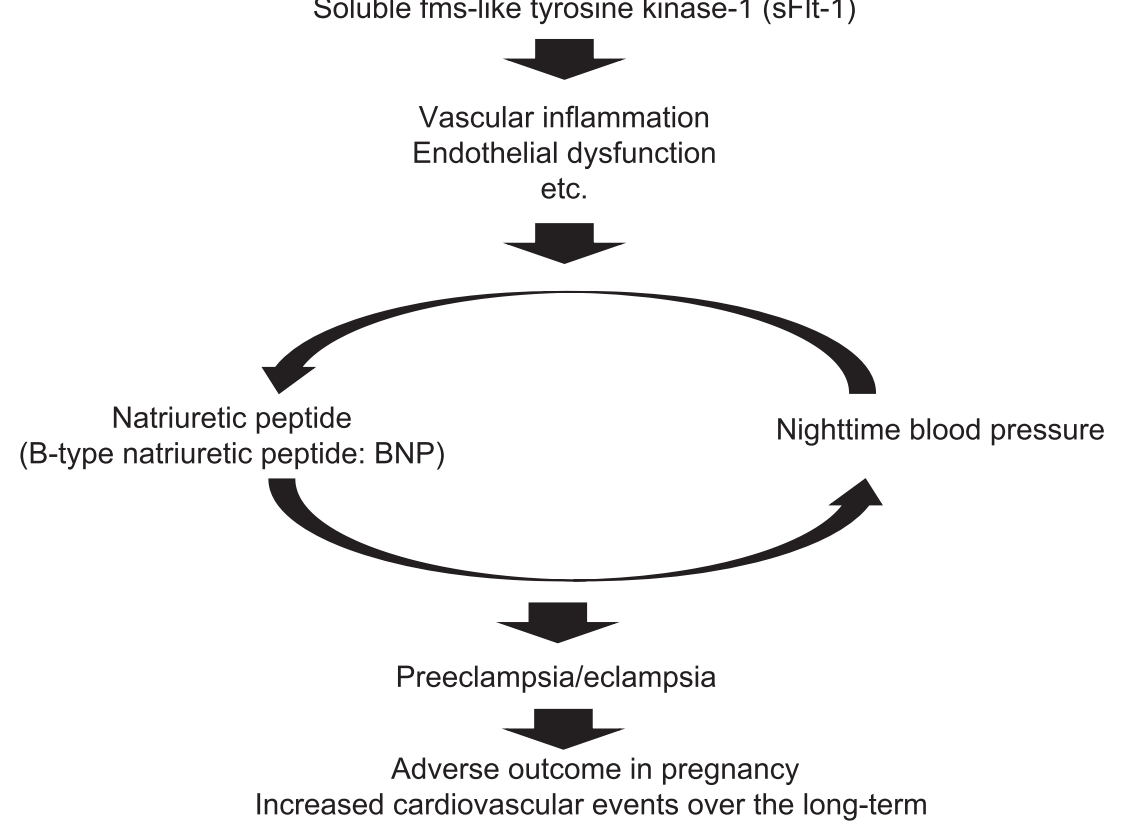

2. Bartsch E, Medcalf KE, Park AL, Ray JG. Clinical risk factors for pre-eclampsia determined in early pregnancy: systematic review and meta-analysis of large cohort studies. BMJ. 2016;353:i1753.

3. Brown MA, Magee LA, Kenny LC, Karumanchi SA, McCarthy FP, Saito S, et al. Hypertensive disorders of pregnancy: ISSHP classification, diagnosis, and management recommendations for international practice. Hypertension. 2018;72:24-43.

4. Whelton PK, Carey RM, Aronow WS, Casey DE Jr, Collins KJ, Dennison Himmelfarb C, et al. 2017 ACC/AHA/AAPA/ABC/ ACPM/AGS/APhA/ASH/ASPC/NMA/PCNA guideline for the prevention, detection, evaluation, and management of high blood pressure in adults: a report of the American college of cardiology/ American heart association task force on clinical practice guidelines. J Am Coll Cardiol. 2018;71:e127-e248.

5. Wu DD, Gao L, Huang O, Ullah K, Guo MX, Liu Y, et al. Increased adverse pregnancy outcomes associated with stage 1 hypertension in a low-risk cohort: evidence from 47874 cases. Hypertension. 2020;75:772-80.

6. Salazar M, Espeche W, Sisniguez C, Minetto J, Balmin E, Soria A, et al. Nocturnal hypertension and risk to develop early-onset preeclampsia in high-risk pregnancies. Hypertension Res. 2021. https://doi.org/10.1038/s41440-021-00740-z.

7. Onoue K, Uemura S, Takeda Y, Somekawa S, Iwama H, Imagawa $\mathrm{K}$, et al. Reduction of circulating soluble FMS-like tyrosine kinase-1 plays a significant role in renal dysfunction-associated aggravation of atherosclerosis. Circulation. 2009;120:2470-7.

8. Kameda R, Yamaoka-Tojo M, Makino A, Wakaume K, Nemoto S, Kitasato L, et al. Soluble Fms-like tyrosine kinase 1 is a novel predictor of brain natriuretic peptide elevation. Int Heart J. 2013;54:133-9.

9. Hoshide S, Kanegae H, Kario K. Nighttime home blood pressure as a mediator of $\mathrm{N}$-terminal pro-brain natriuretic peptide in cardiovascular events. Hypertens Res. 2021. https://doi.org/10.1038/s41440-02100667-5.

10. Tomitani N, Kanegae H, Kario K. Reproducibility of nighttime home blood pressure measured by a wrist-type nocturnal home blood pressure monitoring device. J Clin Hypertens. 2021. https:// doi.org/10.1111/jch.14342. 